\title{
The impact of digitalisation on the organisational capability changes - Evidence from Serbia
}

\author{
Teodora Slavinski \\ University of Belgrade, Faculty \\ of Organisational Sciences, \\ Belgrade, Serbia \\ slavinskiteodora@gmail.com
}

\author{
Marija Todorović \\ University of Belgrade, Faculty \\ of Organisational Sciences, \\ Belgrade, Serbia \\ marija.todorovic@fon.bg.ac.rs
}

\begin{abstract}
Business across all industries had been influenced by the rise of digitalisation trends. This had provided an imperative for organisations to change in order to remain competitive in the marketplace. Companies had to transform an organisation behaviour, process, or culture in the way which reflected the new business opportunities in digital environment. The following study analyses the implications of digital transformation in the companies located in Serbia, by highlighting the several dimensions of its multiple benefits, recognised from the literature review and empirical research results.
\end{abstract}

Keywords-digitalisation, digital transformation, digitisation, organisational capability, resource-based view, competitive advantage, digital age.

\section{INTRODUCTION}

In the last few years, the topic of digital transformations has reached the highlight of scholar's interests. This is justified by the increased presence of the digital transformation process in almost all business fields. It has equally occupied nongovernment and government sector, so it's now clear that the boundaries of influence will continue to expand by intense usage of transformation process. Therefore it can be concluded that digitalisation is considered as the crucial transformation of nowadays society, reflecting on business and everyday life [1]. This prediction is especially influenced by the fact that the process has been found in many government strategies for national development and rebranding programs. In those cases, interpretations of the digitalisation and digitisation processes are taken from companies, which are making significant investments in digital research and its usage for some time now. It has been recognised that digitalisation will provide integration, transparency, productivity and the opportunity to transform their supply chain operating model.

Various perspectives on digitalisation and digital transformation in a multitude of industries are also considered as the results of different implications of the process, such as the one "that corporations can become more efficient and sustainable nowadays". changing business models, purchasing processes and the transformation of local to global etc. [1]. Rapid changes appeared in informational technologies field, had a significant influence into creating the new digital market as the dominant business environment, the organisations have been forced to adapt themselves to the new circumstances by transforming their usual functions and processes.

The Internet and digital technologies have created new opportunities for internal organizational improvements, as well as the external potentials for taking an active role in the global market and with global competitors. This means that with a proper digital adaptation and by updating their strategies in the way to reflect the new business possibilities, organisations can maximise the multiple benefits of digitalisation processes. There are several dimensions of organisational changes through digitalisation and all of them lies into the proper analysis and the organisational capacity [2]. These changes can be visible in the level of technology, level of organisation and level of workers and employees.

This study aims to examine the benefits of digitisation recognised by companies in Serbia and to emphasise how, in turn, it is necessary for them to adapt their business models and strategic orientations to achieve these recognized benefits. The following paper is organised into several logical parts - the first section consists of theoretical conceptual frameworks, which should phenomenological define the key elements of the digitisation process, highlighting the basic organizational elements for the corporate level strategy definition. After that, through the presentation of the researching results, it will be pointed out to those phenomena that Serbian companies recognise as dominants when it comes to the exploitation of digitisation in the local frameworks, but also establish the parallels with corresponding parts of the recommended literature.

\section{LITERATURE REVIEW}

\section{A. Perspectives of Digitalisation}

Digital transformation is an actively discussed topic by practitioners and academics, from late 1990s. The implementation of digital activities in the organisations is present for more than 30 years. The explanation for the success of this phenomenon, as for its duration and future orientation, can be located in the unbreakable relation between processes of digitalisation and globalisation. The rise of globalisation, as the expansion of the economy beyond 
national borders through digitalisation, can be seen both as the cause and the result of the digital technology exploitation. For instance, Saskia Sassen uses the idea of digitization (in the more expansive way of digitalisation, and which will be explain more in further text) to make a number of arguments about the new, global configurations of "territory, authority and rights" and to express her view about the growth of international market rules and theirs characteristics [3]. On the other hand, Guchinskaia and Tolstikova have shown their interests in this topic by emphasising globalisation's impact on creating a new expression of global society [4].

The communication process is identified as the key aspect for the sustainability of the global society, and digitalisation is also seen as the necessary precondition for it. One of the effects of globalization is the development of cyberspace for different activities, which presents an integral part of communication processes [4]. Ustundag and Cevikcan [5] emphasise this relation between globalization and digitalization by putting it in the context of employment in the Industry 4.0. and explaining that people, due new trends, have started "boundaryless careers" [5]. From these statements, it can be concluded that by the right consultation with the digitalisation process, and with proper usage of digital technologies, the organisation can easily take an active role in the global market, and in that way enforce a significant impact on globalisation phenomenon in practice.

Even though it was already mentioned that the digitalisation was intensively used in the last 30 years in practice, there are different opinions of scholars when it comes to the historical development of the phenomenon. For this purpose, in tendency to review the development of digitalisation through history, in the further text we will try to make the clear distinction between three conceptual terms, which are closely associated in the relevant literature. In this paper, digitisation, digital transformation and digitalisation will be discussed through different emerging concepts.

\section{B. Three conceptual terms - digitisation, digital transformation and digitalisation}

If we tried to pinpoint the moment in which digitisation process has begun, we would find a lot of different standpoints. Vogelsang describes the origins of digitisation by identifying its foundations even so far as the late 17 th century [6]. The explanation lies in the definition of the concept, which describes digitization as the technical process of converting streams of analogue information into digital bits of $1 \mathrm{~s}$ and $0 \mathrm{~s}$ with discrete and discontinuous values. Because of this, Vogelsang considers the scientific activity of Gottfried Leibniz, German philosopher, who completed the initial work on binary number systems, as the earliest expression of digitisation [6]. He goes further with this claim with pointing out the same principle incorporated in the basic form of the
Morse alphabet, which he describes as "a binary system based on only two different states, proved far more resistant to transmission, coding, and decoding errors than alternatives" [7]. Vogelsang refers to Paul Edwards, who identifies Morse code as the concept of binary numbers, which has laid the historical foundations for later developments in computing and digitisation.

On the other hand, many researchers gave their contribution by highlighting other perspectives on analysis of the digitisation process, such as questioning their symbolic and material dimensions. Scientific collaboration between Brennen and Kreiss on defining the conceptual term of digitisation has contributed to better understanding of its material and immaterial dimensions [8]. Basing their stance on Manoff and Hayles' earlier research, they symbolically convey digitisation as the process of converting analogue signals into bits that are represented with $1 \mathrm{~s}$ and $0 \mathrm{~s}$, while its physical manifestation they relate to transistors where digital information are ultimately stored. For this reason, in mediating lbetween the material and the immaterial, the nature of digitising these authors highlight as a unique process $[9,10]$.

The uniqueness lies in the digital transformation of observed information as means of transporting the analogue into digital system. This transforming activity Van Dijk sees as the changed capacity of message to become more universal because every reducing of communicated message to its basic components leads to elimination of potential errors and unnecessary repetitions [11]. This statement is the result of summarising different academic perspectives and implicates to the other aspects of organisational functioning.

The digital transformation process, fundamentally, can be seen as one in which "all signals are chopped into little pieces" [11], which forms a state of "data compression" [12]. "Changing the nature of data, as the initiation of making more clear and useful communicational channel between user and information, and assisted by technological transformation of organisational capacity, leads concurrently to the questioning of informational data originality" [12]. Even if industries have responded by creating a "digital rights management" [8], this question occupied one group of scholars. Some of them believe that transformed digitised information cannot be diminishing or degrading to the original digital object and that they can be used repeatedly by many different people thanks to so-called "zero marginal cost of reproduction" [13, 14]. Others are questioning the monetisation of copyrightable content and the ability to assert enforceable copyright over cultural goods $[15,16,17]$. The reasoning behind this statement lies in the evolvement of digital transformation, which is described by Negroponte, who describes "megadata" as the product of "radical simplification or reduction of information in digital form" [12]. This has been created by system producing process of information about "digital stream by 
distilling signals down to their most basic form" [18]. From this point of view, it is easier to understand the multitude applications of digital transformation process and the high importance of its proper usage. Even if we analyse this phenomenon in the context of legality or surveillance, we can emphasise that digitising information offers significant and meaningful qualities and has become a ubiquitous and widely recognisable concept.

It is not rare to find many differences when it comes to defining three conceptual terms of digitisation, digital transformation and digitalisation. Digitization is considered as the usage of digital technologies to change a business model and provide new business chances [19]. Even if there are some differences between scholars' opinions, the concept of digitalisation is almost always connected with computerisation and technical development. When it comes to defining the conceptual frame of digitalisation, the usual path is to describe the specific possibilities of digital media, their structure and shape, and their influence to the world. "In this sense, digitalisation has come to refer to the structuring of many and diverse domains of social life around digital communication and media infrastructures" [8].

Digital surrounding allows extraordinary usage of digitalisation and its implications, which result in big changes and benefits for the organisation. This is recognisable in all aspect of organisational life - in almost all functions and processes, in internal and external communication, introduction of new business aspects and new professions [19]. The presence of those implications can be felt even beyond, in many different domains of daily life, so it's not unusual to talk about Robert Wachal's concept of "digitalisation of society" [20]. Digitalisation can be seen as the dominant characteristic of the contemporary era [21], the frame of the new infrastructure [11], transformed world [22] or globalisation of economy [23].

Other scholars explain how digitalisation broadly motivates "convergence" of disparate sectors $[8,12,24]$. Brennen and Kreiss have found four different aspects of this convergence - infrastructural, terminal, functional and rhetorical, and market convergence [8].

Whether we argue about digitalisation, digital transformation or digitisation as the phenomenon itself, we have to highlight their presence as the key creator of the new digital order, emphasise their role in creating a modern digital environment and link their proper use with the progress of the organisations. So far, we have strived to define each of these phenomena individually, even if they are inseparable in practice. This paper will further discuss the multiple benefits for the organisations through both digitalisation and digital transformation, as well as digitisation, by emphasising the proper organisational transforming capacity for active participation in the digital environment. Even though the effects of digitalisation have probably not been visible yet for some companies, there are convincing indicators for the progress of digitalisation within economy [25]. While many authors agree that digitalisation process can be applied to almost any type of information, this conversion process implies at the same time the adaptation of organisational capacity by which the organisation adjusts to the necessary conditions required for digital transformation.

\section{Digitalisation and Organisational Capability}

In the world of modern business, which is characterised by frequent turbulences of fast changes, the success of the organisation depends on its ability to adapt to the new environment and needs of the market. The creators of such intensive changes can be quite different, but it is nowadays believed that the main sources of the new transformed business environment are some aspects of the IT revolution, technology growth and globalisation [2]. As this tendency is stimulated by the ideas of the world market as a "market without borders", the concept of digitisation assumes the meaning of the lingua franca of the modern era, as the capacity of facilitating universal communication [11]. By providing instant access to information, the IT revolution changed the roots of the nature of the business environment and thus set the demands for technological development and infrastructural changes to adapt to the modern business rule.

In technological development, organisations have seen the powerful potential of improving the processes of their businesses, as well as acquiring and maintaining competitive advantage. They will adapt their own development strategies and create new ones, by consulting key concepts as creators of the new business context of the Industry 4.0, thus taking part in the global market by using digitalisation properly and using it in its full potential. The ability to change rapidly, to produce creative and innovative solutions, as well as participate in the global market and with global competitors, represent three factors that are crucial for the success of an organisation in a new business environment [26]. These are all the aspects that are taken for corporate level strategy formation , the strategy that will lead the organisation to gain a competitive advantage in digital business environment. The strategy should be created based on environmental business opportunities and threats, to become the basis for competitive advantage.

Between authors, there is an agreement towards the stance that resources are the most important precondition for maintaining a competitive advantage. This is the basic statement for understanding one of the integral parts of strategic management, such as the Resource-based view [26]. The resource-based view represents organisational strategic development as the use of unique organisational resources and capabilities [2]. According to Dess, Lumpkin and Eisner, the essential characteristic of resources as a financial, physical, human, non-material and structural-cultural organisational part is in their uniqueness. Margaret Peteraf continues, by writing about the resource-based view of competitive advantage. She has integrated the 
existing perspectives into new model of resources and firm performance, by emphasising four key conditions underlying sustained competitive advantage. Although it has contributed to an innovative approach, this model is also essentially based on the analysis of elements that guarantee resource uniqueness - their value, rarity, difficulty to substitute and difficulty to imitate [2].

These conditions are related mostly to the intangible resources (human and social capital) as the highest valued organisational units today [27]. Only the part of organisational capital that cannot be imitated, social and human capital, can generate a sustainable competitive advantage, and therefore represent an invaluable organisational component. Therefore, to define organizational capital we must concern its effects on all performance measures [27]. Therefore, the special focus of scholars towards this concept is reasonable and justified. Its definition resides in the intertwinement of different perspectives of internal and external organisational environment. These activities should be carefully considered and should be seen as crucial steps for acquiring competitive advantage since it is only achieved by precisely positioning the organisation by looking at the real state of external indicators and its internal organisational capabilities.

In short, organisational capabilities represent competencies or skills that are used to transform business inputs into desired outputs. Organisations use capacity tangible and intangible resources to leverage organisational capabilities and achieve planned performances [28]. It also refers to organizational culture, structures and relationships, know-how, knowledge sharing, practices etc. [25]. This implicates that human capital and organisational capacity overlap in some to pinpoint.

Human capital is based on learning and experience, and it is also a summary term for the individual resources that enable a person to fulfil a professional role or task. On the other hand, Organisational capacity extends the human capital idea to the organisation. In addition to the employees' human capital, organisations also hold productive knowledge and abilities at a collective level. In this manner, it is not unusual that some author pointed to high importance of "on-the-job training", because it clearly illustrates and emphasises its common effects for employee, in individual level, and for organisational capability, in collective level [29].

In the digital environment and under the pressure of organisational digital transformation, it is also considered that occurred changes had their reflection into the level of employee' required skills. Highly computerised systems produce a large quantity of data which need high-skilled professionals to get adequately utilised [30].

\section{METHODS}

\section{Data and Sample}

In order to examine the chosen hypotheses, we have used a questionnaire as a technique to provide an empirical research. It consists of 45 different questions relating organisational strategies and their connection with the digitalisation process. This questionnaire's structure aimed to track the multitude implications of the different development strategies on digitalisation process and its results. The questionnaire is created by implementation and adaptation of the Norwegian 2017 research named ,The effect of strategic orientation on the commercial exploitation of digitalisation" [31].

\section{Measures and Analyses}

There sample of 50 respondents from the several business industries was grouped into four different categories - IT and telecommunication, Finance and assurance field, Manufacturing and Public sector and public institutions (marked as "The others" in the questionnaire). The questionnaire was distributed to the referent persons in local Serbian firms as well as foreign firms, so the respondents came from diverse sectors and all levels of organisational hierarchy. Criteria being used in firms selection for this survey were that they have more than ten employees, and annual sales greater than 700.000 euros. (according to the current Serbian Accounting law). The respondents had the task of assessing statements depending on the extent to which they agree with them. Therefore they were offered Likert scale (1-5). The offered answers were universal, same for each question - "strongly disagree", "disagree", "neutral", "agree" and "strongly agree". It has been suggested that this comparative method is more effective at eliciting responses than directly asking respondents to provide exact figures [32].

\section{RESULTS}

The final results have shown that $40 \%$ of total respondents came from the IT industry and telecommunication, 28\% from Public sector and public institutions (which are described in research as the "other"), 20\% from Finance and assurance field, and remaining $12 \%$ from Manufacturing. By analysing the obtained results, it is noticed that the largest number of respondents identified the potentials of benefits that could be achieved by properly introducing digitalisation into their organisations.

The precondition for this type of profit is certainly the readiness of the organisation to accept technological and other innovations or to express a proactive attitude towards the development of new technologies. This assumption was rated by $58 \%$ of respondents as the true one, and $16 \%$ of them have shown strong agreement. The other respondents, $18 \%$ of them, showed neutrality when describing their working environment in the context of the above assumption, $6 \%$ disagreement and $2 \%$ extreme disagreement. 
As we have already mentioned, digitisation can bring many benefits to the company, and some of those have been recognised by the respondents as more or less important. For example, even $61.36 \%$ of respondents declared themselves to agree with the positive implications of digitisation and cutting costs in the observed organisations, while $11.36 \%$ said they strongly agreed with this assumption. Only $13.64 \%$ of the respondents showed a negative attitude, while the same number of them was neutral regarding this topic. When considering these percentage indicators, it is not unusual that $58.14 \%$ of the respondents stated that the process of digital transformation in the company is viewed as an effort to increase efficiency, while $16.28 \%$ strongly agreed with this. In contrast, $4.65 \%$ of respondents showed disagreement and $20.93 \%$ neutrality.

It has been shown that the questions of organisational survival in the belonging industry, active participation in global market and getting a competitive advantage can provide many answers. By collecting and analysing the following results, we have identified the crucial components as technological expertise, ability for organisational learning, management's open-mindedness and organisational self-criticism. Out of the total number of respondents, only $2 \%$ strongly disagreed that their companies extract technological expertise from competitors, while $14 \%$ only disagreed. On the other hand, while $32 \%$ of them showed a neutral attitude about this statement, $42 \%$ had expressed agreement and $10 \%$ strong agreement. Ability to learn as the key to competitive advantage has been recognised by $64 \%$ of respondents as important and by $14 \%$ as highly important. Neutrality about this topic characterised $16 \%$ of them, while $6 \%$ had shown negative attitude. There was a diversity of attitudes regarding organisational self-criticism. It has been shown that $6.82 \%$ of respondents estimated their working environment as an environment in which self-criticism is not very appreciated, while $4.55 \%$ expressed a less intense but still negative attitude. Neutrality about this has been shown by $27.27 \%$ of respondents. Further, $52.27 \%$ had identified self-criticism as something recommended and practised in their organisations and $9.09 \%$ as highly recommended.

On the other hand, organisational progressing in digital age is not guaranteed by proper consulting of these explained elements. The statement of believing in the importance of business model reconfiguration for survival in belonging industry has shown that $58 \%$ of respondents agree and $26 \%$ strongly agree with it, while $12 \%$ of total had shown a neutral attitude. Only $4 \%$ of them had expressed disagreement. Even $40.82 \%$ agreed that digitalisation process had given a competitive advantage to their organisations in the belonging business field and $16.32 \%$ expressed strong agreement with this. On the other hand, $26.53 \%$ of total respondents reacted neutrally and $16.32 \%$ with a disagreement. Initiative for digitalisation, in this manner, has been recognised in its full importance by different departments of the company and their cooperation. With this statement, $8.82 \%$ of respondents strongly agreed while $55.88 \%$ agreed. Neutral attitude had been shown by $26.47 \%$ and negative by $8.82 \%$ of respondents.

Digital transformation, with its positive applications in the organisational environment, has been located in the various aspects of business. Therefore, $56 \%$ of total respondents expressed that it can cause the development of new business areas by applying new technology. The strong agreement had been shown by $24 \%$ of them, while $8 \%$ declared themselves neutral. A disagreement has been shown by $12 \%$ of respondents. Those various aspects can be seen in streamline of internal workflow, in creating a better customer experience or in improving the quality of existing services. Implementation of digitalisation to simplify internal organisational workflow had been recognised by $66 \%$ of respondents, and $16 \%$ had a strong agreement with this. Only $4 \%$ thought that this way of digitalisation usage is not the characteristic of their organisations and $14 \%$ of respondents had declared themselves as neutral. When it comes to creating a better customer experience, the major number of respondents (even $74.47 \%$ of them) had recognised digitalisation as its crucial stimulant, and $14.89 \%$ highly agree with this statement. Neutrality about this topic has been shown by $6.38 \%$ and disagreement by just $4.25 \%$. Because of this, it is not unusual that only $4.35 \%$ of respondents disagree with an idea of digitalisation as the existing service for quality improvement or that $17.4 \%$ had reacted neutral. On the contrary, $58.69 \%$ agreed with this statement and $19.56 \%$ strongly agreed.

In the end, $48 \%$ of respondents agreed that digitalisation process has its usage in gathering customer insights and $8 \%$ had shown their strong agreement. In other hand, we can find that $4 \%$ estimated this statement with a strong disagreement, and $24 \%$ with disagreement. Neutral attitude had been shown by $16 \%$ of respondents. Respondents had shown that one of the dominant developmental directions in their work environments is to keep customers satisfied, to archive and track their user experience. They expressed their opinion about development of the new products by using technological innovations that contribute to the satisfaction of the users of company services. When they were asked whether the use of sophisticated technologies contributes to the development of their new products, the respondents made the following statement - $8.69 \%$ disagreed, $8.69 \%$ stayed neutral, $69.56 \%$ had shown positive attitude and $13.04 \%$ strongly agreed. This was reflected in their opinion about the high technological quality of products, but there are noticeable differences in these responses. A strong disagreement has been expressed by $4.35 \%$ of respondents, and the same number expressed themselves negatively. More of them, $30.43 \%$ had taken a neutral stand, while $41.3 \%$ of respondents agreed. A strong agreement had been shown by $19.56 \%$ of respondents. 
Technical innovations and stimulating attitudes about professional development are the characteristics of the respondents' organisations, which turned out to use the digital transformation and digitisation in general in their functioning. That is why $52 \%$ of respondents agreed with the statement that technical innovation had been easily accepted in their organisations, $8 \%$ strongly agreed, while $18 \%$ of them decided to stay neutral. On the other hand, $18 \%$ of total respondents disagreed with this topic and $4 \%$ strongly disagreed. It turned out that the opinions were different when they were asked about whether employee learning is seen as an investment or an expense in their companies. While $57.14 \%$ has shown positive stance and $18.36 \%$ an extremely positive, $12.24 \%$ of them stayed neutral. It is a bit concerning that $6.12 \%$ of respondents expressed themselves negatively and $6.12 \%$ extremely negative.

\section{V.DISCUSSION AND LIMITATIONS}

We have strived to define the multiple benefits for the organisations through digitalisation, reflected into different fields of changes (social, economic, technology) [24]. The obtained results of the research have confirmed some of the central arguments mentioned in the literature.

First, it has been shown that significant component of informational technology' value in the process of digitalisation, represents organisational capacity to enable new aspects of complementary organisational investments such as business processes and changed work practices [33]. Second, these investments, in turn, improves firm's performances: cost reduction, the increase of productivity, inputs savings, improved product quality or improvements in intangible aspects such as communication with customers, high flexibility [28]. It has been pinpointed that indicators from practice summarised in the results, confirmed some of the existing theoretical frameworks - there has been represented that digitalisation can lead to higher product quality or better conditions for product development [28]. Further, specific implications of organisational transformation by digitalisation are related to the reduction of coordination costs - due to usage of technologies to facilitate communication among employees.

The summarised empirical research results, which have illustrated the dominant opinion of respondents from IT and Telecommunication sector, had highlighted the technological expertise and other expertises as key element for gaining the competitive advantage in digital business environment. This is in line with the assertions of resource-based view of the firm [34]. It turned out that this statement is also substantially agreed by the respondents from the industry of Manufacturing.

When we analysed the responses of the employees from the Finance and Insurance sector, we have noticed that they unanimously highlighted their usage of digitalisation to optimise the website and applications. Digitalization contributes to their customer-centric business, companies in this field can use new technologies and master online and mobile channels to improve customer's experience [35]. In the end, it is important to emphasise the dominant attitude shown by respondents from the Government sector. They have strongly agreed with the statement that digitalisation has a high potential for streamline internal workflow and for creating a better customer experience. This can be seen as the precise illustration of the institutional theory, referred by many researchers [36]. "ICT included in e-government is considered a proper institution, taking into account its relationships with the surrounding environment, organisational aspects, stakeholders, communications with other government agencies, interaction with citizens and socio-economic impact on the country, in general, and the government, in particular. ICTenabled transformed government results in enhancing government's transparency and accountability, which in turn affects the organisational aspect and institutional arrangements, as well as the way government institutions work and interact with their stakeholders, including citizens" [37].

Taking into account the obtained results of the research, we consider that there is an evident contribution of this study, but that it would be much more significant if the research was repeated on the larger number of respondents. This would provide a precondition for data processing with quantitative methods so that the final realisation would allow for a more accurate and realistic insight. In this way, we would approach the observed research topic by consulting the eminent authors' measurement instruments and accessed research from a different perspective.

\section{CONCLUSION}

Under pressure of the digital global efforts to make the market more transparent and worldwide available, businesses are undertaking their digital transformations, rethinking what customers value most and creating operating models that take advantage of what's newly possible for competitive differentiation. The organisations see digital transformation as the development of a unified platform which exploiting digital technologies in a manner that fundamentally changes their usual business practice. The expected results from this transforming process cannot be visible instantly in the organisation, but its future implications can fundamentally change business efficiently and make the organisation an active part of the global market.

\section{ACKNOWLEDGEMENT}

In this paper are presented the results of the researching project "Research of Contemporary Tendencies of Strategic Management with the Application of Specialized Discipline Management in the Function of Competitiveness of the Serbian Economy", no 179081, and it has been financed by the Ministry of Education, Science and Technological Development of the Republic of Serbia. 


\section{REFERENCES}

[1] J. Hagberg, M. Sundstrom, and N. Engels-Zandén, "The digitalisation of retailing: an exploratory framework," International Journal of Retail \& Distribution Management, vol. 44 July 2016, pp. 694-712.

[2] G. Dess, G. T. Lumpkin, and A. B. Eisner, "Strategic Management: Creating Competitive Advantages", McGrawHill Education, 2013.

[3] S. Sassen, "Globalization and its discontents: essays on the new mobility of people and money," Berkeley Planning Journal, vol.4, December 1999, pp. 117-120.

[4] O. Guchinskaia, and I. Tolstikova, "Communication in Cyberspace," Digital Transformation and Global Society, Russia, First International Conference. St. Petersburg, Russia, June 2016, pp. 64-71.

[5] A. Ustundag, and E. Cevikcan, "Industry 4.0: Managing The Digital Transformation", Springer International Publishing, 2018.

[6] M. Vogelsang, "Digitalisation in Open Economies: Theory and Policy Implications", Physica-Verlag Heidelberg, 2010.

[7] P. N. Edwards, "The closed world: Computers and the politics of discourse in Cold War America", MIT Press, 1997.

[8] J. S. Brennen, and D. Kreiss, "Digitalisation", in The International Encyclopedia of Communication Theory and Philosophy, K.B. Jensen, E.W. Rothenbuhler, J.D. Pooley and R.T. Craig, Eds. Chichester: Wiley-Blackwell, 2016, pp. 556566.

[9] M. Manoff, "The Materiality of Digital Collections: Theoretical and Historical Perspectives," Libraries and the Academy, vol. 6, August 2006, pp. 311-325.

[10] N. K. Hayles, "Translating Media: why we should rethink textuality," The Yale Journal of Criticism, vol.2, Fall 2003, pp. 263-290.

[11] J. A. G. M. van Dijk, "The Network Society: Social Aspects of New Media”, 2nd ed., vol. 2, London: Sage, 2005, pp. 684 700 .

[12] N. Negroponte, "Being Digital", New York: Alfred A. Knopf, 1995.

[13] L. Lessig, "Code: And Other Laws of Cyberspace”, New York: Basic Books, 2006

[14] E. Brynosofisson, and A. McAfee, "The Second Machine Age: Work, progress, and prosperity in a time of brilliant technologies", New York: W.W. Norton \& Company, 2014.

[15] M. Ananny, and D. Kreiss, "A new contract for the press: Copyright, public domain journalism, and self-governance in a digital age," Critical Studies in Media Communication, vol. 28, October 2011, pp. 314-333.

[16] J. Boyle, "The public domain: Enclosing the commons of the mind", New Haven, CT: Yale University Press, 2008.

[17] W. W. Fisher, "Promises to Keep: Technology, law, and the future of entertainment", Stanford, CA: Stanford University Press, 2004

[18] J. M. Owen, "The Scientific Article in the Age of Digitalisation", Dordrecht: Springer, 2007

[19] N. Žarkić-Joksimović, and S. Marinković, "Conference Report Symorg 2018 - Doing Business in the Digital Age: Challenges, Approaches and Solutions," Management: Journal of Sustainable Business and Management Solutions in Emerging Economies, vol. 23, 2018, pp. 87-89.
[20] S. Mihelj, A. Leguina, and J. Downey, "Culture is digital: Cultural participation, diversity and the digital divide," New media \& Society, vol.1, July 2019, pp. 1465-1485.

[21] M. Castells, "End of Millennium: Information Age Series", Wiley-Blackwell, 2010.

[22] S. Verhulst, "About Scarcities and Intermediaries: the Regulatory Paradigm Shift of Digital Content Reviewed." in The Handbook of New Media, L. A. Lievrouw and S. Livingstone, Eds. London: Sage Publications, 2002, pp. $432-$ 447.

[23] K. K. Cetina, and U. Bruegger, "Global Microstructures: The Virtual Societies of Financial Markets," American Journal of Sociology, vol.107, January 2002, pp. 905-950.

[24] J. Beniger, "The Control Revolution", Cambridge: Harvard University Press, 1986.

[25] C. Harteis, "The Impact of Digitalisation in the Workplace: An Educational View", Springer International Publishing, 2018.

[26] M. A. Coutler, "Strategic Management in Action", Pearson Publishing, 2012.

[27] O. Ludewig, and D. Sadowski, "Measuring Organisational Capital," Schmalenbach Business Review, vol.61, 2009, pp. 393-412.

[28] S. Dutta, O. Narasimhan, and S. Rajiv, "Conceptualizing and Measuring Capabilities: Methodology and Empirical Application," Strategic Management Journal, vol.26, pp. 277285, 2005.

[29] G. S. Becker, "Investment in Human Capital: A Theoretical Analysis," Journal of Political Economy, vol. 70, pp. 9-49, 1962.

[30] S. Arvanitis, "Computerization, workplace organisation, skilled labour and firm productivity: Evidence for the Swiss business sector," Economics of Innovation and New Technology, vol.14, 2005, pp. 225-249.

[31] A. Eitrem, and L. Öberg, "The effect of strategic orientation on the commercial exploitation of digitalisation - A study on digitalisation in Norwegian companies", unpublished.

[32] D. Tomaskovic-Devey, J. Leiter, and S. Thompson, "Organisational survey response," Administrative Science Quarterly, vol.39, September 1994, pp. 439-457.

[33] E. Brynjolfsson, and M. H. Lorin, "Beyond Computation: Information Technology, Organisational Transformation and Business Performance," Journal of Economic Perspectives, vol.14, Fall 2000, pp. 23-48.

[34] D. P. Lepak, and S. A. Snell, "The Human Architecture toward a Theory of Human Capital Allocation and Development," The Academy of Management Review, vol. 24, January 1999, pp. 31-48.

[35] C. Scardovi, "Digital Transformation in Financial Services", Springer International Publishing, 2017.

[36] W. Leodolter, "Digital Transformation Shaping the Subconscious Minds of Organisations: Innovative Organisations and Hybrid Intelligences", Springer International Publishing, 2017.

[37] M. T. Mahmood, "Does Digital Transformation of Government Lead to Enhanced Citizens' Trust and Confidence in Government," Springer International Publishing, 2019. 